\title{
Las estatuas-menhir noroccidentales en contexto: conectividad y conexiones materiales durante el Bronce Tardío/Final
}

\author{
Northwestern Statues-Menhir in Context: \\ Connectivity and Material Connections During the Late Bronze Age
}

\author{
Javier RodRÍGUEZ-CORRAL ${ }^{1}$ \\ Institute of Archaeology \\ University of Oxford. United Kingdom \\ javier.rodriguezcorral@arch.ox.ac.uk
}

Recibido: 30-05-2014

Aceptado: 11-12-2014

\begin{abstract}
RESUMEN
Este artículo analiza las estatuas-menhir noroccidentales que se distribuyen en el área comprendida entre los valles del río Duero y el río Miño, pero que descubrimientos recientes han extendido a regiones fuera de este área nuclear. Partiendo de tres aspectos claves para su interpretación (la cronología, su relación con el paisaje y su sentido iconográfico), se examinan las relaciones entre estas formas materiales y un paisaje socio-material de acción especifico (las formas socio-materiales de interacción propias del Bronce final atlántico). Para ello, se tiene en cuenta diferentes conexiones materiales (presencia, encuentro, coexistencia, hibridación, etc.) que permiten contextualizar las estatuasmenhir dentro de un proceso histórico particular: la integración del noroeste de la península Ibérica en un contexto de relaciones mediterráneo-atlánticas, en la segunda mitad del II milenio a.C.
\end{abstract}

Palabras Clave: Estatua-menhir, Bronce Tardio, Bronce Final, paisajes de movilidad, conectividad, hibridación, Noroeste de Iberia.

\begin{abstract}
ABSTACT
This paper examines the northwestern staute-menhirs which are distributed in the area between the valleys of the river Duero and the river Miño, but that recent findings have extended to other regions outside that core area. Taking three key issues on the interpretation of them (chronology, landscape and image) as a starting point, this analysis focuses on the material relations between these material forms and a specific socio-material landscape of action (the sociomaterial forms of interaction characteristic to Atlantic Late Bronze Age). To this end, it takes into account different material connections (such as presence, encounter, coexistence, hybridization, etc.) that enable to contextualize the statues-menhir as part of a specific historical process: the integration of the northwestern Iberia in the interaction contexts between the Mediterranean and the Atlantic since the end of the $2^{\text {nd }}$ millennium $B C$.
\end{abstract}

KEY words: Statue-Menhir, Late Bronze Age, Landscapes of Mobility, Connectivity, Hybridization, Northwestern Iberia. 


\section{Introducción}

Las estatuas-menhir noroccidentales son un tipo de forma material característico de la plástica prehistórica de la península Ibérica. Se trata de un grupo bien definido que se distribuye en la región comprendida entre los valles de los ríos Duero y Miño, en las regiones de Tras-os-Montes y la Beira Alta y en la provincia de Salamanca (fig. 1). Tres aproximaciones han sido utilizadas para su estudio: (1) modelos que las integran en esquemas explicativos de la plástica de la prehistoria de la Península; (2) estudios que tienen su base interpretativa en las arqueologías del paisaje y del territorio; y (3) análisis iconográficos que estudian estos artefactos como imágenes materiales.

En el primer caso, las aproximaciones sustentadas en metarrelatos difusionistas y evolutivos han situado las estatuas-menhir dentro de tipologías globales de la plástica prehistórica, centrándose especialmente en el análisis de sus orígenes. En este sentido, como ha señalado Díaz-Guardamino (2010: 25), se ha tendido en ocasiones a establecer para toda la plástica un origen común en el contexto megalítico. La ventaja de este tipo de perspectivas reside en la capacidad que tienen para desarrollar seriaciones y marcos crono-tipológicos que han resultado esenciales para el análisis cronológico, debido a la ausencia de infor- mación estratigráfica (Jorge 1986; Barceló 1989; Almagro-Gorbea 1993). El punto débil radica en su efecto homogeneizador y unilineal que obvia la diversidad de contextos históricos de los que la plástica prehistórica pudo haber formado parte.

Las perspectivas del paisaje y del territorio han permitido pensar las estatuas-menhir más allá de estos esquemas. Partiendo de su ubicación en el paisaje, se ha prestado atención a la relación que estos monolitos establecen con zonas de paso o fronterizas, o con áreas propicias para actividades como la agricultura, la ganadería, o la minería (Barceló 1989; Galán y Ruiz-Gálvez 2001; Vilaça et al. 2001; Bettencourt 2005; Fábrega et al. 2011; Alves y Reis 2011; Comendador et al. 2011). La principal dificultad a la que se enfrenta este tipo de aproximaciones es la ausencia de contextos primarios para la mayoría de las estatuas-menhir, debido a que han aparecido habitualmente reutilizadas en contextos modernos. Con todo, no debería suponer un problema para el macro- y meso-análisis del paisaje, ya que podemos asumir que estas formas materiales fueron obtenidas del entorno inmediato para su reaprovechamiento en época moderna.

Finalmente, el tercer nivel de estudio ha tenido en consideración aproximaciones iconográficas centradas en la descripción detallada de los grabados y en la interpretación de las estatuasmenhir como imágenes de poder (Bueno 1983;

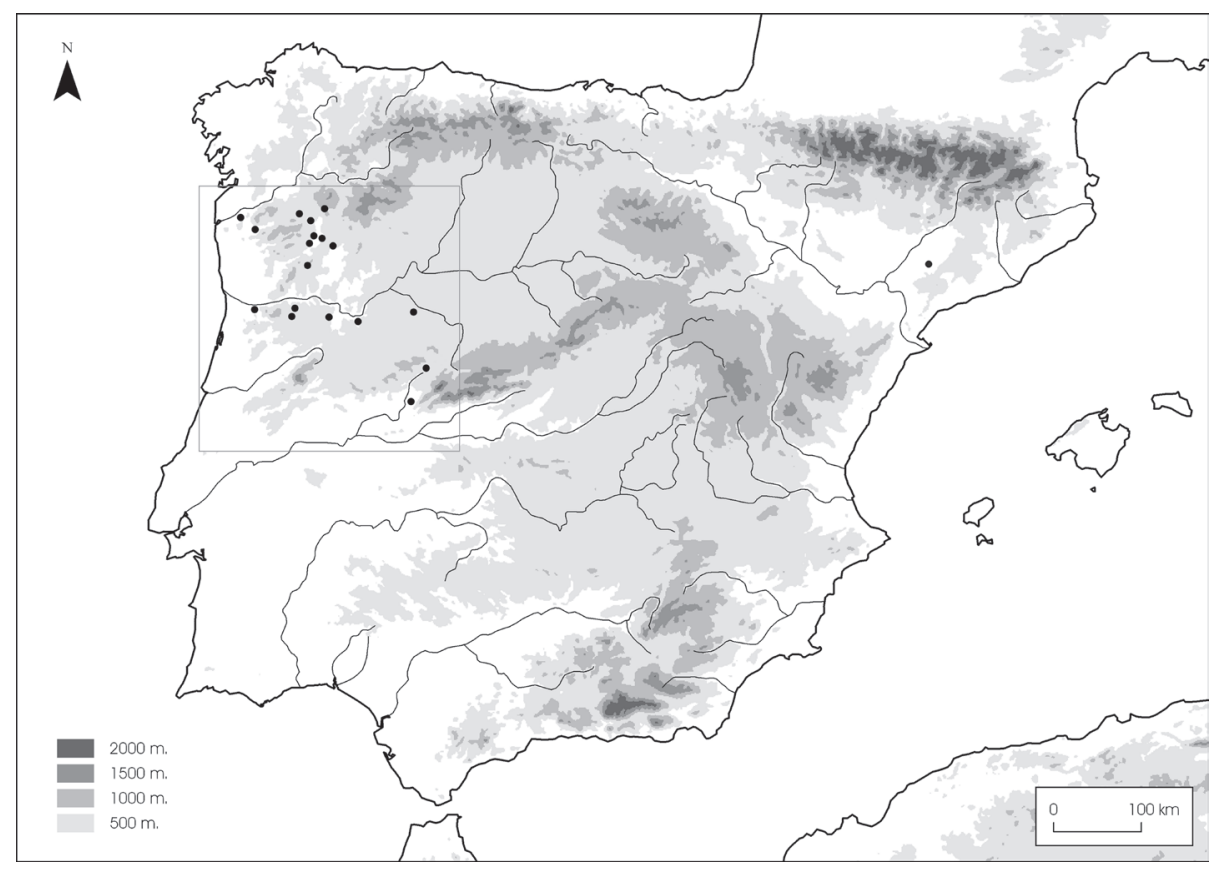

Fig. 1. Mapa de distribución de las estatuas-menhir. 
Jorge 1995; Díaz-Guardamino 2011). En este caso, el hallazgo de muchos de los ejemplares fuera de sus contextos originales limita el análisis micro-escalar, impidiendo inferir las cualidades y relaciones que estas imágenes establecen con el entorno material inmediato.

El propósito de este artículo es contribuir al estudio de estas formas materiales tomando en consideración los aspectos claves que han definido su interpretación tal como acabamos de señalar: la cronología, su relación con el paisaje y su sentido iconográfico. Partiendo de estos puntos, se examinan las relaciones materiales entre estas estatuas-menhir y un paisaje sociomaterial específico de acción: las formas materiales de interacción en la región atlántica durante el Bronce Tardío/Final (1400/1200-900/850 cal. a.C.). Para ello, se analizan diferentes conexiones materiales (presencias, encuentros, coexistencia, hibridaciones, etc.) que permiten contextualizar las estatuas-menhir dentro de un proceso histórico determinado: la integración del noroeste de la península Ibérica en un contexto de relaciones mediterráneo-atlánticas.

\section{Cronología}

Una cuestión central en el estudio de las estatuasmenhir ha sido su contextualización cronológica y cultural, caracterizada por la escasez de datos y divergencias en la interpretación. La estela de Longroiva (Jorge 1995), datada en el Bronce Inicial o Medio, y la pieza de São João de Ver, en el Bronce Final/primera Edad del Hierro (Jorge y Jorge 1990; Queiroga 2003: 85), representan los límites cronológicos propuestos para estas manifestaciones materiales. Dentro de este arco, el grupo principal de estatuas-menhir se ha situado tradicionalmente en el Bronce Final (Almeida y Jorge 1979; Jorge y Almeida 1980; Jorge y Jorge 1983; Almeida 1983; Jorge 1986; Sanches y Jorge 1987; Jorge y Jorge 1990; Jorge y Jorge 1993; Sanches 1995; López Plaza et al. 1996: 301; Bettencourt 2005: 171; González-García 2009; Comendador at al. 2011; Fábrega et al. 2011). Otros autores han propuesto cronologías más antiguas, entorno al Bronce Inicial o Bronce Medio, bien para algunas de las piezas (Baptista 1995; Vilaça et al. 2001; Alves et al. 2011; Cruz y Santos 2011), bien para todo el grupo escultórico (DíazGuardamino 2012: 390).

No obstante, este envejecimiento cronológico de las estatuas-menhir requiere ser matizado.
Debido a la falta de contextos primarios y datos estratigráficos, el único modo de datar estos monumentos queda supeditado a los paralelos que se pueden establecer con otras formas materiales, o entre sus iconos y sus posibles referentes metálicos. En este sentido, las cronologías de armas utilizadas como referentes también están sujetas a debates, en donde los datos y las asociaciones contextuales se entretejen aportando fechas y seriaciones que están lejos de ser seguras. Las espadas representadas, por ejemplo, en monumentos como Valdefuentes, Tremedal y Preixana han sido asimiladas a tipos IIb de la seriación de Almagro, cuyas cronologías no son precisas, pero que permite situarlas genéricamente en algún momento del Bronce Pleno (1700-1200 a.C.). Diversos argumentos, sin embargo, apuntan a una cronología más tardia. En primer lugar, la empuñadura de Valdefuentes tiene su mejor referente real en las empuñaduras de la espada $\mathrm{n}^{\mathrm{o}} 1$ de Guadalajara y de Abía de la Obispalía (Cuenca), asociadas en el último caso a brazaletes Villena/Estremoz (Almagro 1972; Brandherm 1998). En segundo lugar, el filo recto con el que se representan estos grabados, como ha señalado Díaz-Guardamino (2010: 165), parece indicar que estas armas fueron más tardías: concretamente, estoques del tipo IIc. Y en tercer lugar, este tipo de espadas aparece en estelas alentejanas asociadas a hechas de enmangue directo. Todo ello, permite proponer una cronología para estas manifestaciones en el Bronce Tardío/Final.

Los autores que proponen cronologías más antiguas recurren a las fechas post quem de depósitos de armas consideradas referentes de los grabados. Dejando a un lado la dificultad que a veces entraña defender tales asociaciones, el uso de estas fechas para datar las estatuas-menhir, en nuestra opinión, las envejece injustificadamente. La cronología post quem de un tipo de artefacto no tienen por qué coincidir en el tiempo con las prácticas de representación o depósito. En la estatua-menhir de Valdefuentes, por ejemplo, se representa una alabarda que ha sido asociada al tipo Montejicar. Mientras que algún depósito admite datar este tipo en el Bronce Inicial (c. 2000-1700/1600 AC) (Díaz-Guardamino 2010: 193), la misma alabarda que se representa en Valdefuentes se documenta en estelas alentejanas, en este caso, junto a espadas como las grabadas en las estatua-menhir y a hachas de enmangue directo que remiten a cronologías del Bronce Tardío/Final (Torres 2008: 80). 
Se debe tener en cuenta el carácter multi-temporal (Olivier 1999) de los diferentes conjuntos de artefactos depositados o representados para datar estos monumentos. Los objetos que definen la biografía del personaje pueden ser más antiguos que la estatua-menhir donde se representan y el origen de su producción más antigua que los diferentes momentos de uso. Formas de conectividad socio-material -herencias, intercambios, pactos, relaciones de reciprocidad, etc.- pueden reunir objetos de diferentes lugares y tiempos que son decisivos en la vida de estos personajes. Trasladar simplemente fechas post quem de un tipo objetual a contextos de depósito o representación del mismo, suministra fechas, que al obviar diversas variables - circulación y recirculación, perduración, reutilización, imitación, etc.-, pueden envejecer injustificadamente los monumentos y sus contextos de acción.

El carácter diacrónico de los grabados plantea otro problema. Las estatuas-menhir son formas materiales construidas procesualmente. Las asociaciones de grabados con referentes reales suministran dataciones que, lejos de fechar la estatua-menhir u otras formas materiales, pueden datar diferentes momentos en su historia. Un buen ejemplo es la ya citada estela de Longroiva. A tenor del tipo de grabado y de los elementos representados, parece muy probable que la ejecución de su iconografía responda a momentos diferentes (Díaz-Guardamino 2010: 136): mientras la alabarda y el puñal parecen ser los elementos más antiguos, el arco y el motivo subrectangular - de la misma tipología que los grabados en los monolitos de Millarón o São João de Ver- respondería a fechas más tardías.

Algunos paralelos esgrimidos para envejecer las estatuas-menhir obvian alternativas en la elección de los referentes. Ejemplos de ello son la asociación que algunos autores establecen entre los collares múltiples representados de Faiões o Nave 2 y las gargantillas de tiras (1700-1550 a.C.) (Díaz-Guardamino 2010: 242) o la vinculación entre el motivo decorativo en espina de pez documentados en los ejemplares de Ermida y Nave 2 con arte rupestre del noroeste (Baptista 1985). En el primer caso, es posible considerar otros referentes - no gargantillas, sino pectorales o collares múltiples-, del ámbito atlántico y mediterráneo con los que los iconos guardan mayor isomorfismo. Entre ellos, por ejemplo, pectorales del ámbito del Mediterráneo occidental como los documentados en el mundo balear (Delibes y Fernández-Miranda 1988: 122) o del ámbito at- lántico como el pectoral de Gleninsheen (O'Toole 2012: 22-23) o el collar múltiple de Sintra (Armbruster 1995). En el segundo caso, el motivo en espina de pez encuentra sus mejores paralelos en objetos y formas materiales (calderos metálicos, hachas de talón, estelas del suroeste, cerámica, etc.) propios de contextos materiales del Bronce Tardío/Final.

Se documentan, asimismo, estatuas-menhir que remiten con certeza al Bronce Tardío/Final. Además del ya citado ejemplar de São João de Vêr, un conjunto de estatuas-menhir, como tendremos ocasión de ver en otro apartado, permite establecer conexiones con formas materiales particulares de este periodo. El isomorfismo entre las armas representadas en el monumento de Chaves y aquellas documentadas tanto en la estela alentejana de Mouriços como en diversas estelas de guerrero-adscribibles a las clases A, B y K de Brandherm (2007: 136-138)- resulta ser una evidencia clara.

Teniendo en cuenta las cronologías propuestas por los diferentes autores, así como las consideraciones que se acaban de plantear, se debe asumir un marco temporal para las estatuas-menhir noroccidentales centrado en el Bronce Tardío/ Bronce Final, sin obviar que la biografía de estas formas materiales pudo incorporar contextos de acción en momentos más tempranos. En este sentido, se podrían señalar dos circunstancias históricas: la generalización del metal y de los artefactos metálicos en la construcción identitaria de la Edad del Bronce -en este contexto aparecerían las primeras manifestaciones- y los procesos de conectividad y movilidad dentro de economías de reciprocidad durante el Bronce Tardío/Final -con el protagonismo del motivo subrectangular.

\section{Paisaje e imagen}

El mayor número de estatuas-menhir se localiza en torno a los ríos Duero y Támega, extendiéndose también a provincias como la Beira Alta y Salamanca (Vilaça 2011). Estos monolitos se distribuyen en áreas de tránsito. Su ubicación en el paisaje desvela una estrecha relación con ríos -Faiões, Chaves, Bouça, Muiño de San Pedro o Nave- y zonas de tránsito por las que posteriormente transcurrirán vías romanas -São João de Ver, Marco, Muiño de San Pedro, Vilar de Santos, Tameirón o Ataúdes- (Díaz-Guardamino 2010: 190; Comendador et al. 2011; Vilaça et al. 2001). Por su parte, los ejemplares de Tremedal, 
Valdefuentes (Salamanca), junto a monumentos como Segura de Toro (Cáceres), se sitúan en las inmediaciones de la ruta natural que une el norte y el sur de la región occidental de la península Ibérica, por donde posteriormente transcurrirá la vía de la Plata.

Las estatuas-menhires, por tanto, formaron parte activa en la construcción de paisajes de movilidad durante la prehistoria. El valle del río Duero facilita un flujo de relaciones y movimientos entre, por un lado, la costa atlántica y Tras-osMontes y, por otro, el noroeste y el centro de la Iberia Atlántica. En tres de las posibles zonas de paso que facilitan rutas de tránsito entre la meseta y el noroeste de Iberia se documentan estelas o estatuas-menhir antropomorfas. Mientras que dos de estas zonas están relacionadas con lugares de paso del río Duero, la tercera está relacionada con el río Támega y la vega de Chaves-Verín (fig. 2), una zona bien comunicada que da acceso a las tierras interiores del noroeste ricas en minerales (Sousa 1996: 95-97). Por otro lado, hacia el este, un corredor natural conecta las tierras de Tras-osMontes/Alto-Duero con el sur de Salamanca y el norte de Cáceres (Jorge 1990: 208). El análisis mediante SIG de la relación entre la posición de las estatuas-menhir y las áreas de movilidad en la zona de Verín ha permitido constatar la proximidad de estas formas materiales a zonas de paso potencial (Fábrega et al. 2011: 317).

La localización de las estatuas-menhir y otras formas materiales en zonas de paso se ha relacionado con la trashumancia (Ruiz-Gálvez y Galán 1991; Ruiz-Gálvez 1998; Galán y Ruiz-Gálvez 2001) y los recursos mineros (Vilaça 2001 et al.; Bettencourt 2005). Ambos aspectos parecen ha-

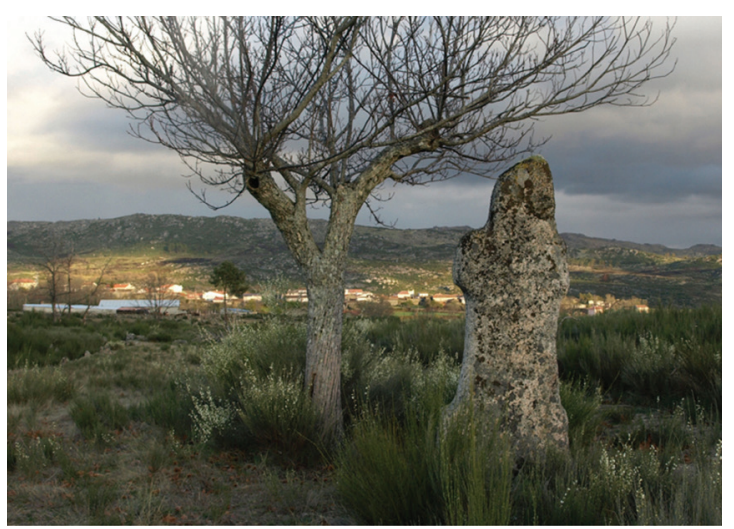

Fig. 2. Estatua-menhir de Marco (Vila Real) in situ, en un área de paso próxima a una calzada romana, en la planicie fluvial de rio Támega. ber contribuido a establecer una amplia red de relaciones socio-materiales de carácter suprarregional. En este sentido, las publicaciones de los últimos hallazgos (Vilaça 2011; Alves y Reis 2011) reiteran una relación entre estas formas materiales y las zonas ricas en oro y estaño. De este modo, la obtención de minerales pudo jugar una papel especial en los procesos de conectividad y movilidad durante la Edad del Bronce (Alves y Reis 2011: 164), a medida que una cultura material en oro y bronce se convirtió en un elemento clave en la construcción de las identidades de los individuos (Comendador et al. 2011).

Se ha esgrimido su función como marcadores territoriales o de caminos en estos contextos de movilidad (Ruiz-Gálvez y Galán 1991; Galán 1993; Jorge 1995). Con todo, el estudio de la relación entre la ubicación de las estatuas-menhir y la movilidad potencial en la zona de Verín, aunque relaciona las estatuas-menhir a estos lugares, constata que se sitúan en posiciones no visibles desde las líneas de flujo (Fábrega et al. 2011: 317). Esta distribución vinculada a zonas de paso no preeminentes permite pensar que fueron lugares especiales, sin una lógica programada, creados dentro de procesos de inscripción en el paisaje (Connerton 1989) derivados de estar y transitar la geografía a lo largo del tiempo. Resulta interesante considerar la posibilidad de que funcionaran, tal como propone Díaz-Guardamino (2006: 21-23), como marcadores de lugares destinados a rituales de conmemoración, por ejemplo, de individuos fallecidos. Una interpretación similar ha sido igualmente propuesta para las estelas del Suroeste (Celestino 2001: 279). Más allá de su función señalizadora, las estatuas-menhir debieron construir lugares específicos, en el sentido heideggeriano del término, al transformar (monumentalizar) aquellos espacios donde se erigieron, ayudando a crear sentido en paisajes de movilidad.

Finalmente, el último nivel de análisis se centra en la performatividad de la imagen. Las estatuasmenhir son representaciones minimalistas que, a través de diferentes técnicas escultóricas, materializan el cuerpo -más social que anatómico- de un tipo muy concreto de individuo. En estas formas materiales se suprimen muchas cualidades estéticas -movimiento, actitudes, gestos, etc.-, formalizando un poderoso acto de abstracción. Como ocurre en otros contextos, no se percibe un intento de definir una biografía personal más allá de su relación con las armas y las insignias y su posición en el paisaje. 
En los monumentos se esbozan la cabeza, el cuello y los hombros, mediante el uso del bulto redondo. El rostro se representa con gran esquematismo, aunque a veces haya existido una clara intención de delimitarlo. Sus rasgos básicos se señalan a través del grabado. En algunos casos se trazan los ojos, la nariz y la boca, mientras que en otros se añaden elementos tales como las orejas. En ocasiones, la representación del rostro queda reducida a un único rasgo como los ojos. Algunos autores han interpretado los surcos horizontales grabados a la altura del tórax como la representación de costillas (Santonja y Santonja 1978: 20; López et al. 1996: 302). Mientras las extremidades superiores se representan en pocas ocasiones, las extremidades inferiores son siempre eludidas.

El recurso al esquematismo y minimalismo en la historia de la representación del cuerpo, como ha señalado recientemente Robb (2009: 174), se encuentra asociado frecuentemente con la promoción de un mensaje simplificado y poderoso. El protagonismo en las estatuas-menhir es para las armas y símbolos que pueden figurar en todas sus caras. Se representan individuos que portan alabardas, espadas, puñales, tahalís o cascos. Asimismo, los surcos horizontales a la altura del tórax han sido interpretados por algunos autores como corazas o como corazas inspiradas en costillas (véase Díaz-Guardamino 2010: 144). Otros elementos representados pudieron ser collares $\mathrm{u}$ otro tipo de objeto de prestigio o rango, mientras el motivo sub-rectangulares, situados mayormente en el anverso, se interpretan como pectorales.

Esta economía de la representación, que materializa un enunciado conciso y estratégico, resulta coherente con los paisajes de movilidad y de encuentro entre individuos y grupos sociales de diferente procedencia. Lo que las estatuas-menhir pierden en detalles y en matices se obtiene en inmediatez y compresibilidad inter-contextual. Los elementos aludidos, relacionados con la construcción de la identidad y el poder funcionan dentro de una "ideología semiótica" (Keane 2003) que necesita tan sólo la vinculación del cuerpo de piedra y los objetos representados sobre su superficie, en el contexto del paisajes de los que forman parte.

Las estatuas-menhir, en el contexto de estos paisajes de tránsito entre territorios puede relacionarse, tal como ha sido señalado por Jorge (1999: 122), con un cambio en la estrategia de construcción del poder y la identidad durante el Bronce Tardío/Final, que pasa de utilizar el espacio necropolitano tumular, a utilizar los nuevos lugares que las estatuas-menhir crean. Se trata de lugares para negociar y construir el poder y la identidad (Jorge 1995; Bueno et al. 2008; DíazGuardamino 2010) tanto por su capacidad de inscripción -monumentalización del espacio- como por su capacidad de incorporación -como lugar para la acción ritual- (Connerton 1989). El poder performativo de las estatuas-menhir, aunque similar al que pudieron tener las estelas del suroeste, difiere de ellas en que incorpora la tridimensionalidad y la necesidad de transitar y rodear la estatua-menhir para aprehender la ideología semiótica que materializa. De este modo, también parece alentar una interacción más íntima entre ella y su audiencia, lejos de la simple visión frontal que el código visual de las estelas demanda.

En suma, un conjunto de evidencias interpretativas pueden ser resumidas: (1) las estatuasmenhir se vinculan con áreas ricas en minerales $\mathrm{y}$ tienen su sentido en paisajes de movilidad y procesos de conectividad; (2) estos monumentos funcionaron activamente durante el Bronce Tardío/Final, aunque dicho fenómeno debió iniciarse con anterioridad; (3) estos monolitos tienen capacidad no solo para representar, sino también para construir lugares en el sentido heideggeriano; y (4) estas formas materiales se adscriben a un contexto temporal donde surge una producción de objetos metálicos (cobre, bronce y oro) y donde estos objetos y su representación intervienen activamente en las construcción de la identidades.

\section{Estatuas-menhir en contexto: hibridación e interacción suprarregional}

No es mi propósito en este apartado rastrear de modo sistemático la circulación de objetos en el paisaje del Bronce Tardío/Bronce Final, sino desarrollar una comprensión de las conexiones materiales entre el Mediterráneo y el Atlántico en el área occidental de la Península. Por esta razón, presto atención a determinadas producciones de oro y bronce, entendidas como cultura material dedicada a la creación de identidades, que desde la segunda mitad del II milenio a.C. participó, junto a las estatuas-menhir, en la creación de estos paisajes de conectividad.

El oro y el bronce, en un contexto de creciente demanda, por su escasez y la concentración de los puntos de obtención en áreas específicas y mayormente marginales (Bradley 2013), alentó procesos de movilidad e interacción -circulación de personas, objetos, conocimiento y valores so- 
ciales- y procesos de vinculación -alianzas políticas regionales y tras-regionales-, destinados a construir y sostener las redes de interacción. Como consecuencia de estos procesos de conectividad, los individuos adoptaron y adaptaron cultura material y la integraron dentro de nuevas prácticas sociales, dando lugar a socio-materialidades propias de estos contextos. Estas dinámicas se evidencian, por ejemplo, en la biografía de artefactos de los ámbitos tecnológicos Sagrajas/ Berzonaca (S/V) y Villena/Estremoz (V/E), que se encuadran dependiendo de los autores en diferentes momentos dentro del Bronce Tardío y Bronce Final (Ruiz-Gálvez 1993: 49, 69; Perea 2005; López Castro 2008: 281). En el depósito Abía de Obispalía, los brazaletes tipo V/E se asocian con las empuñaduras que sirven -junto a la documentada en la espada $n^{\circ} 1$ de Guadalajarade referentes materiales de algunas representaciones en estatuas-menhir o estelas alentejanas.

Tres tipos de conexiones materiales suprarregionales en las producciones metalurgias del oro acreditan identidades socio-materiales surgidas de la interacción: (1) depósitos formados por objetos atlánticos y mediterráneos; (2) objetos híbridos creados a partir de objetos -o fragmentos de estos- pertenecientes a ámbitos tecnológicos diferentes; y (3) objetos de tipología atlántica fabricados con tecnología mediterránea.

El primer tipo de conexión material está formado por los objetos mediterráneos y atlánticos que fueron depositados juntos en diversos lugares del oeste y sur de la península Ibérica. Tres depósitos ejemplifican este tipo de conexión: Berzocana (Cáceres), Bélmez (Córdoba) y Baleizâo (Beja). El primero de ellos lo componen dos torques de oro del ámbito tecnológico atlántico y una pátera con omphalos procedente del Mediterráneo oriental (Perea 2005: 100). El depósito de Bélmez (Córdoba) lo constituye un torques atlántico y un amasijo de oro con objetos de origen Mediterráneo (Perea y Armbruster 2008: 516). Y el depósito de Baleizâo (Beja) consta de un torques, un brazalete, un lingote, varias hachas, seis pesas, una pasta vítrea e hilo de filigrana. En este caso resulta interesante, además de la asociación de objetos atlánticos y mediterráneos, la aparición de un lingote y de piezas métricas que lo vinculan a actividades de intercambio, como gran número de depósitos en el norte de Portugal, donde ambos elementos son recurrentes (Torres 2008: 64-67; Vilaça 2008a, 2008b).

El segundo tipo de conexión material lo componen objetos fabricados a partir de la reutilización de dos o más piezas antiguas de los ámbitos tecnológicos $\mathrm{S} / \mathrm{B}$ y $\mathrm{V} / \mathrm{E}$, usándose también en su reelaboración tecnología mediterránea $(\mathrm{Pe}-$ rea y Armbruster 2008: 516-517). El Brazalate de Cantonha y el collar múltiple de Sintra (Silva 1986) materializan estos procesos (fig. 3). La primera pieza, depositada en el área nuclear de las estatuas-menhir, fue creada a partir de dos brazaletes tipo $\mathrm{S} / \mathrm{B}$ y uno $\mathrm{V} / \mathrm{E}$, a los que se añadieron hilos de filigrana por soldadura. La localización de estos objetos híbridos en Guimarães y Sintra, revela que los mismos fenómenos de hibridación se están dando, tanto en el norte como el sur, o que los objetos híbridos, cuya materialidad condensa una fuerte conectividad, circulan en ambas regiones.

La explicación de estos procesos de mestizaje son difíciles de determinar. Probablemente, las diferentes partes de estos objetos, teniendo historias separadas o diferentes, fueron reunidas y rehechas para construir un nuevo objeto (una nueva identidad) acorde con una nueva situación. Como ha sido señalado para contextos del Bronce Final, las nuevas identidades en este periodo emergen a
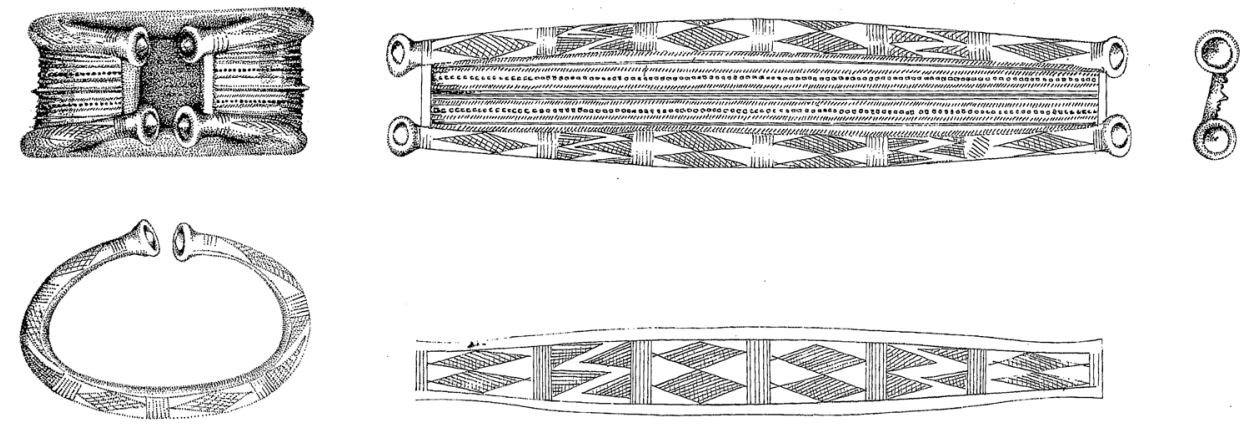

Fig. 3. Arriba: brazalete de Cantonha (Braga); abajo: brazalete de Chaves (Vila Real) tipo S/B. (Silva 1986). 
través de las cualidades metonímicas y metafóricas de las cosas. La agrupación de objetos para dar lugar a una nueva materialidad que filtra ámbitos temporales y espaciales diversos podría responder a un carácter relacional en la construcción de la personalidad e identidad durante el Bronce Final (Bruck 2006: 297). Sea como fuere, esta hibridación debe ser vista como resultado de una interacción en expansión entre individuos procedentes de diferentes contextos creando diferentes situaciones de contacto.

Finalmente, el tercer tipo de conexión son las imitaciones de una tecnología visualizada pero no asimilada (Armbruster y Parreira 1993: 78-83). Mientras desde un punto de vista tipológico estos artefactos pertenecen al ámbito atlántico, desde un punto de vista tecnológico se adscriben al ámbito Mediterráneo. En este sentido, un ejemplo interesante es el depósito de Herdade de Álamo (Beja), ubicado en la misma área que el depósito de Baleizâo. Los dos torques que componen este depósito son tipológicamente iguales al resto de torques del ámbito tecnológico atlántico S/B. Sin embargo, como ha señalado Perea (2005), fueron fabricado con tecnología mediterránea: los aros son huecos y se utilizó la soldadura y la filigrana en su fabricación. Este tipo de objetos evidencian la existencia de contactos directos y personales, y el establecimiento de relaciones entre élites locales y de origen mediterráneo (Perea y Armbruster 2008: 515-517). En el depósito de Herdade de Álamo encontramos una última conexión material. Junto a los dos torques, apareció un collar en el que se representa esquemáticamente una figura humana del mismo tipo que se representan en estelas de guerrero. Como han señalado Perea y Armbruster, la aparición en estas estelas de elementos iconográficos procedentes del Mediterráneo dota de mayor fuerza la posible relación entre el collar del Álamo y los protagonistas de estas estelas y por extensión de todo el depósito (Perea y Armbruster 2008: 516).

En la transición entre el Bronce Final y la Primera Edad del Hierro (siglos VIII-VI a.C.) se documentan depósitos de artefactos mediterráneos como los de La Aliseda (Jaén), Sines (Alentejo) o Baião (Porto). Este último, formado por un collar y dos pares de arracadas (Silva 1986), se localiza en la sub-región del Támega, área donde se distribuyen el mayor número de estatuas-menhir. La tecnología, tipología e iconografía de las piezas, así como su presencia en la región noroeste de Iberia, permiten situarlo en el marco de procesos de conectividad con nuevos agentes mediterrá- neos. Este tipo de depósitos han sido interpretados por Ruiz-Gálvez (1992: 238) como dotes de mujeres del ámbito fenicio con miembros de élites locales. La institución del matrimonio es la forma más clásica del pacto social (Sahlins 1972: 222) que posibilita la creación de una estructura reglada de relaciones que garantice la movilidad y el intercambio pacífico (Strathern y Stewart 2005: 235). Los diferentes tipos de conexiones que se constatan en los artefactos que acabamos de ver, materializan, a diferentes niveles (producción, circulación, acumulación, etc.) procesos de encadenamiento (Chapman 2000) en la construcción de las identidades entre individuos o élites del ámbito atlántico y mediterráneo.

Además de bienes de prestigio, las élites pudieron incluir materias primas como los metales entre los elementos de intercambio. Ejemplos de ello podrían ser las hachas de talón que circularon en las mismas áreas de distribución de las estatuas-menhir y las estelas de guerrero de tipo básico (Monteagudo 1977; Martín, 1999: 59-61). La circulación o reproducción de estas piezas también se constata dentro de redes de intercambio e interacción con el Mediterráneo antes de la presencia fenicia, tanto en depósitos de las islas Baleares (Guerrero 2008) como de otras regiones del Mediterráneo central (Giardino 1995).

Su reducida resistencia mecánica y la conservación en muchos casos de sus conos de fundición, aconsejan descartar la función de las hachas de talón como simples herramientas. Tras analizar sus pesos, estas piezas han sido interpretadas como lingotes que se ajustan a modelos métricos propios del Mediterráneo (Galán y Ruíz-Gálvez 1996; Galán 2005: 471). Aunque no se puede descartar que su circulación haya formado parte de modos de transacción de orientación mercantil, la distinción entre regalos y mercancías durante el Broce Final no parece clara (Pare 2013). Así, dentro de economías basadas en la reciprocidad, estos objetos podrían haber sido apreciados más como objetos de valor que como un simple recurso metálico. Su papel en las redes de intercambio atlánticas y atlántico-mediterráneas pudo ser similar al señalado recientemente para los lingotes de piel de toro chipriotas dentro de las redes de intercambio mediterráneas. Se ha podido constatar que, a pesar de que estos lingotes circularan por Grecia continental, los artefactos en esta región fueron fabricados con minerales de yacimientos locales. Por tanto, como Steel (2013: 96) ha planteado, estos lingotes debieron circular como regalos entre élites, y no como materia 
prima para la elaboración de objetos. De modo similar, las hachas de talón pudieron funcionar en un contexto donde la reciprocidad de presentes fue clave para la sociabilidad, la construcción de identidades y la creación de lazos regionales y suprarregionales.

La tendencia en las postrimerías del Bronce Final y principios de la primera Edad del Hierro, como ha señalado Galán (2005), fue la acumulación de las hachas de talón en depósitos (Samieira, Hio, Estea, Alcabre, etc.) situados en las zonas costeras (Rías Baixas y norte de Portugal) que cobran un protagonismo central dentro de la nueva ruta marítima que une el noroeste de la Península con el ámbito fenicio. El fenómeno de reorientación de su circulación hacia estas áreas costeras pudo acontecer en el contexto de sustitución de las redes de interacción propias de sistemas de reciprocidad entre élites del Bronce Tardío/Final por un nuevo sistema de relaciones alentado por los fenicios desde Onuba y Gadir. De este modo, mientras que las hachas de talón pudieron funcionar como bienes en redes de intercambio y reciprocidad entre élites en un contexto de interacción regional y suprarregional a través de redes principalmente terrestres, no parece que lograran ser asimiladas por la nueva ruta marítima de naturaleza mercantil, lo que explicaría su amortización en depósitos a partir de ese momento.

Las Rías Baixas -y, más concretamente, la Ría de Vigo-, ejemplifican este cambio. Grabados rupestres, espacios sagrados semíticos y objetos de origen Mediterráneo y del sur peninsular (González-Ruibal 2004) permiten constatar cómo esta región se inserta en un proceso que termina con su integración en la ruta marítima que origina el conjunto de asentamientos y factorías fenicias en la costa portuguesa desde el siglo VIII a.C. (Arruda 2002). En el primer caso, se documenta una hibridación mediterráneo-atlántica: se representan embarcaciones mediterráneas junto a grabados de tipología atlántica de la Edad del Bronce. En el segundo caso, dos templos betílicos de origen fenicio, materializan nuevas condiciones de interacción. Estos espacios sagrados, ubicados en una península (Alcabre) y una isla (Toralla), reproducen espacios de intercambio característicos del sur de la Península (González-Ruibal 2006). Ambos templos surgen tras un ambiente material del Bronce Final a tenor del conjunto de objetos de este periodo que aparecen en los niveles previos. En el caso del templo de Alcabre, se documenta además estructuras de cabañas en ma- terial perecedero y material cerámico y metálico que se datan en los siglos VII-VI a.C. Sintomáticamente, este nuevo complejo - que materializa un nuevo modelo de conectividad-, se levantó a escasos metros de un depósito de hachas de talón.

En suma, el establecimiento de la ruta marítima atlántica creó un nuevo modelo hegemónico de movilidad e intercambio que transformó los tipos previos de conectividad entre el sur y el noroeste de Iberia. Esta nueva ruta integró la región noroccidental en una red comercial en manos de una clase mercantil que trasporta mercancías en barco. Previamente, sin embargo, los objetos de prestigio que llegan a la Beira Alta y al norte de la cuenca del río Duero, la producción de objetos híbridos o la circulación de hachas de talón, debieron formar parte de redes de intercambio dentro de paisajes de movilidad fundamentalmente terrestres, que conectaron el sur y norte de la región atlántica peninsular en el marco de economías de reciprocidad entre élites.

\section{Las estatuas-menhir: individuos en movi- miento}

La evidencia de conexiones suprarregionales en una cultura material dedicada a la creación de las identidades permite contextualizar y entender la lógica material e iconográfica de las estatuasmenhir. La hibridación o las conexiones materiales que encontramos en la metalurgia del oro o en las hachas de talón se manifiestan igualmente en las estatuas-menhir. Mientras la tecnología o tipología de la metalurgia atlántica permanece homogénea hasta el Bronce Tardío/Final, a partir de ese momento se complejiza para luego hibridarse con tecnología y tipología mediterránea, dando productos coherentes con nuevos momentos de interacción.

Las estatuas-menhir condensan conexiones en el tiempo y en el espacio que materializan la trasformación social y el contexto socio-material en el que están embebidas. Por un lado, se constata una conexión temporal: por su morfología y dimensiones, así como por su ubicación en el paisaje, como ha señalado Alves y Reis, parecen heredar del megalitismo el carácter monumental y conmemorativo de los menhires (2011: 176). De hecho, algunos de estos ejemplares (Chaves, Bouça o Muiño de San Pedro) fueron previamente menhires fálicos (Jorge y Jorge 1983; Bettencourt 2005) que, en un momento dado, necesitaron ser repensados y reciclados. Sea como fuere, 

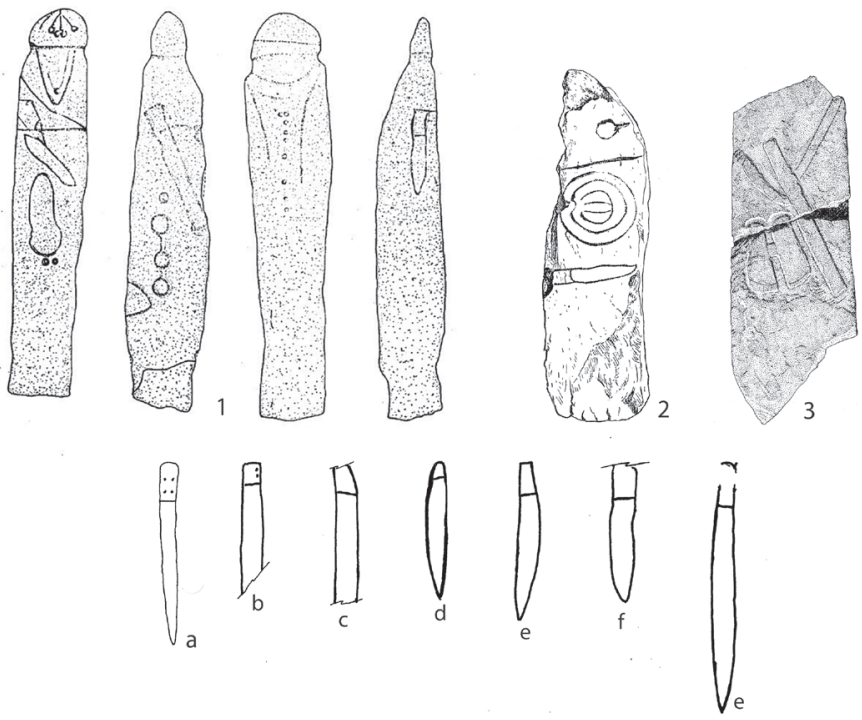

Fig. 4. 1. Chaves (Jorge y Jorge 1990); 2. Tres Arroyos (Celestino 2001); 3. Gomes Aires (Almagro Gorbea 1966). 4. Espadas representadas en estelas del suroeste (Brandherm 2007): a. Eiras; b y d. El Manjar de los Puercos, c. Salvatierra de Santiago; e. El Oreganal I; f. Tres Arroyos; g. Los Herraderos.

fueron antropomofizados y se le añadieron armas y símbolos en un nuevo contexto que parece estar relacionado con dos circunstancias históricas señaladas al principio de este artículo. La primera de ellas tiene que ver con las consecuencias sociales que supuso la elaboración y uso de objetos metálicos. El grabado de armas es una prueba del prestigio que podemos asociar a la producción metalúrgica (Bettencourt 2005: 171). La segunda circunstancia entronca con la conexión espacial que se materializa en las estatuas-menhir: tanto el grabado de emblemas subrectangulares como otros motivos iconográficos revelan una vinculación con ámbitos de interacción con el mundo meridional y mediterráneo durante el Bronce Tardío/Final.

\subsection{Iconografías y geografías compartidas}

Diferentes conexiones entre las formas materiales propias del sur de Iberia (estelas-guijarro, estelas alentejanas o estelas de guerrero del suroeste) y las estatua-menhir noroccidentales permiten trazar claras vinculaciones entre ambas regiones $\mathrm{y}$, por extensión, con el Mediterráneo.

La estatua-menhir de Chaves es un buen ejemplo (fig. 4). El monumento muestra claros vínculos con formas materiales del sur tales como estelas alentejanas y estelas guerreros. La figura alargada y rectangular que se representa en su cara 2, interpretada como una espada que pende de un cinturón, establece una conexión con la iconografía de la estela alentejana de Gomes Aires (Almagro Basch, 1966: 120), en donde se grabó la misma figura. Esta estela ha sido datada en el Bronce Tardío/Bronce Final y ha aparecido junto a una estela con escritura del suroeste (Díaz-Guardamino, 2010: 322). Asimismo, la representación de una espada o puñal en el lateral de la estatua-menhir muestra isomorfismo pleno con el arma grabada en la estela del suroeste de Tres Arroyos (Alburquerque, Badajoz). En realidad, esta conexión icónica se debe a que ambos grabados responden a un tipo de representación de espada, de perfil ancho y empuñadura simple y recta, que se documenta en estelas de guerrero de estilo básico en su área de distribución más septentrional (Beira Baja, Beira Alta, Badajoz y Cáceres) y que se solapan con el área de las estatuas-menhir noroccidentales.

En esta área interior, concretamente en la Beira Baixa, se localiza el conjunto de estelas de San Martinho (Castelo Branco). Lo componen tres piezas halladas en la ladera de una colina donde se ubica un asentamiento del Bronce Final y de la primera Edad del Hierro. En los ejemplares números I y II se grabaron elementos que evidencian conectividad con el mundo mediterráneo dentro de un horizonte Bronce Tardío/Final. Mientras en la primera se documentan dos in- 

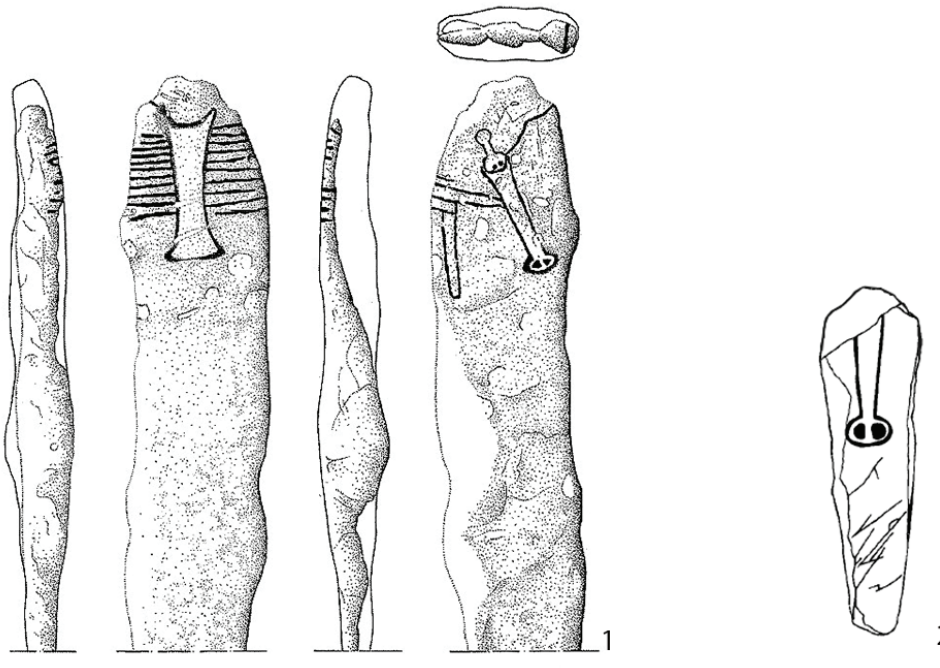

2

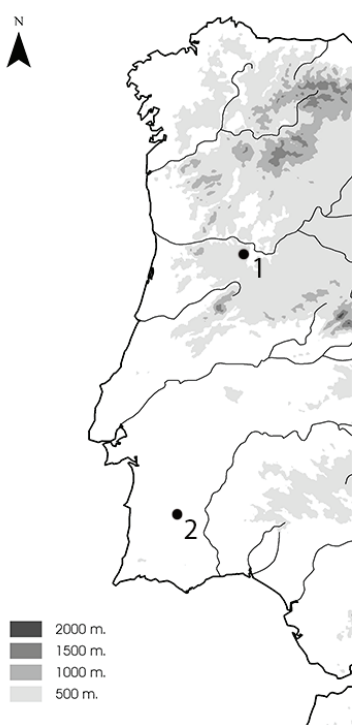

Fig. 5. Isomorfismo icónico entre: 1. La estatua-menhir de Ataúdes (Vilaça et al 2001) y 2. La estela de Muriços (Díaz-Guardamino 2010). [1:3].

dividuos con cuernos, en el segundo ejemplar se representan una escena de caza, una fíbula de codo y un espejo. La estela de San Martinho III, por su parte, filtra dos conexiones. En primer lugar, el monumento funciona al mismo tiempo con la lógica de una estatua-menhir y de una estela. Mientras que la figura humana que se representa en su anverso parece indicar que el monolito funcionó como soporte de la imagen, el cinturón y faldellín grabado debajo de la imagen parecen utilizar el propio volumen del monolito como metáfora del cuerpo del personaje. En segundo lugar, la figura humana se representa a través del motivo sub-rectangular. En las áreas de transición entre estelas del suroeste y estatuas-menhir septentrionales, ambas formas materiales parecen hibridarse y el motivo sub-rectangular trascender el mundo de las estatuas-menhir, documentándose en contextos materiales propios del sur, y en relación con iconografías mediterráneas. Esta misma lógica material e iconográfica se advierte en el ejemplar de en Preixanes (Lérida), considerado como una estatua-menhir, aunque fuera del área de distribución atlántica.

Se constata otro tipo de hibridaciones, bien a través de objetos mediterráneos y atlánticos representados en las estatuas-menhir, bien a través de formas materiales del sur y el noroeste de Iberia en las que se representan los mismos objetos. En el primer caso, un buen ejemplo, son las alabardas tipo Montejicar (ámbito mediterráneo) y tipo Carrapatas (ámbito atlántico), representadas en Valdefuentes y Longroiva, respectivamente. Ambos modelos tienen mapas de distribución amplios que evidencian su papel en las redes de intercambio. El segundo ejemplo lo encontramos en el vínculo iconográfico norte-sur documentado en los monumentos de Ataúdes (Guarda) y Mouriços (Beja). Mientras el primero es una estatua-menhir noroccidental con emblema subrectangular, el segundo, hallado en una necrópolis de la primera Edad del Hierro (Ourique) del sur de la península -en un contexto probablemente de reutilización-, ha sido definido como una estela alentejana. En ambos casos se representa exactamente la misma contera de espada (fig. 5). Este isomorfismo y el carácter fracturado del ejemplar de Mouriços ha permitido a algún autor sugerir que en realidad se trata de una estatua-menhir (Diaz-Guardamino 2010). La primera interpretación plantearía una iconografía común entre las estelas alentejanas -formas materiales meridionales como representación de objetos mediterráneos- y las estatuas-menhir noroccidentales. La segunda señalaría la presencia de éstas últimas en el sur de la península. Sea como fuere, ambas opciones permiten establecer una conexión material entre ambas regiones.

Finalmente, el motivo decorativo de espina de pez documentado en estatuas-menhir como Ermida o Nave 2 sirve para rastrear otra conexión material atlántico-mediterránea. Este elemento se documenta reiteradamente en los objetos en 


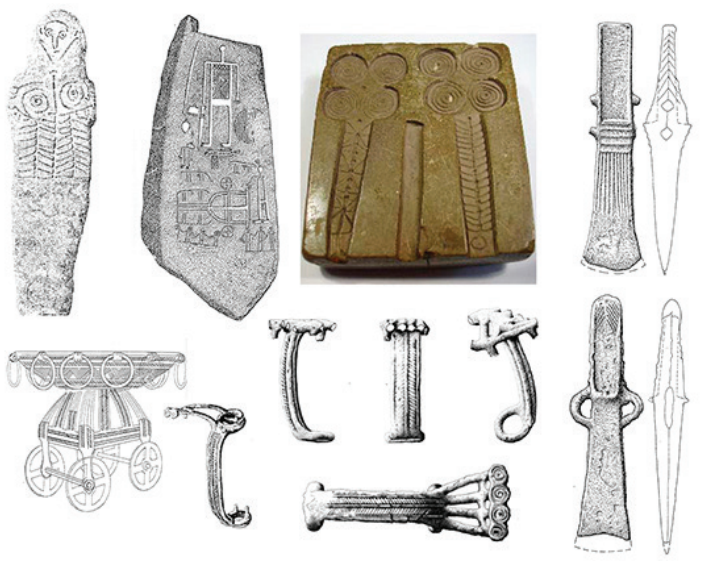

Fig. 6. El motivo de "espina de pez": 1. Ermida; 2. Ategua, Córdoba; 3. Campo Redondo, Gouveia; 4. Baiões, Viseu; 5. Monte Sa Idda, Cerdeña; 6. Monte São Martinho, Castelo Blanco; 7. Pé do Castelo, Beja; 8. San Simón da Costa, Lugo; 9. Bardaos, A Coruña. (A partir de Silvia, 1986; Monteagudo

1977; Celestino 2001; Vilaça 2008b).

bronce que durante el Bronce Tardío/Final aparecen en el mediterráneo -por ejemplo, en Monte Sa Idda, Cerdeña- y el atlántico -por ejemplo en el depósito de Baiões, en la Beira Alta- debido a los procesos de conectividad y movilidad entre ambos ámbitos. Por tanto, este esquema decorativo resulta ser un indicador material de los flujos de interacción con el ámbito mediterráneo durante el Bronce Tardío/Final (fig. 6).

$\mathrm{Si}$ las estatuas-menhires noroccidentales presentan elementos que conectan sus iconografías con las formas materiales del suroeste, se puede igualmente constatar otra conexión material entre estos ámbitos, a través de la presencia de estelas del suroeste en la propia área noroccidental. Las estelas de guerreros son una evidencia material clave para estudiar la interacción entre el Sur y el interior de la Península. Los ejemplares más septentrionales se localizaban en la Beira interior (Curado 1984: 11), constatándose la co-presencia de ambas formas materiales en la periferia de sus áreas de distribución. Senna-Martínez (2011: 293) ha vinculado recientemente la producción de bronces al sur del valle del río Tajo desde el Bronce Tardío, con la necesidad de un abastecimiento regular de estaño en forma de casiterita en los placeres aluviales de las dos Beiras, lo que explicaría la localización de estelas en estas áereas. El reciente descubrimiento de tres estelas de guerrero en el noroeste de Iberia parece advertir que las geografías de movilidad, materializadas en estos monu-
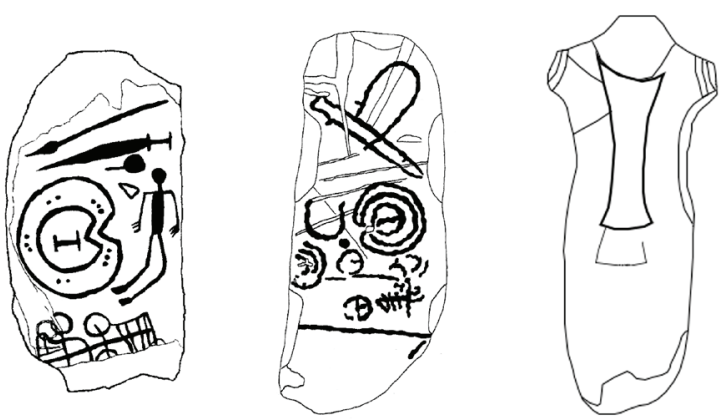

Fig. 7. Hibridación entre estatua-menhir noroccidental y estela del suroeste: a. Estela de Solana de Cabañas (Cáceres), b. estela/estatua-menhir de Pedra Alta (Ourense) y c. estatua-menhir de Faiões

(Chaves).

mentos, alcanzan el noroeste peninsular donde se sitúa el área nuclear de estatuas-menhir.

La estela más meridional de estos tres hallazgos recientes es Pedra da Atalaia (Guarda) localizada en la Beira Alta, en el sector norte de la Serra da Estrela (Vilaça et al. 2011). Por su parte, la estela de Tojais (Vila Real) se localiza en el extremo occidental del macizo de Chaves (fig. 7). En este caso, su ubicación es relevante por tres razones. En primer lugar, en esta zona se encuentra una de las principales zonas de extracción de estaño del norte de Portugal, y se constata una importante explotación tanto de este mineral como de oro en época antigua. En segundo lugar, la estela de Tajáis comparte paisaje con la estatua-menhir de Cruz de Cepos, localizada muy cerca de la primera $\mathrm{y}$ ambas ocupan un área fronteriza y de paso. $\mathrm{Y}$, en tercer lugar, este paisaje de altura es el último punto que debe superarse, viniendo desde el sur, antes de descender hacia la planicie fluvial del Támega (depresión Verín-Chaves), área estratégica de comunicación donde se localizan el mayor número estatuas-menhir (Alves y Reis 2011), y área tradicional de captación de artefactos meridionales (González-Ruibal 2006-2007).

La tercera estela, Pedra Alta (Castrelo do Val, Ourense), se sitúa en el extremo norte de esta planicie fluvial encajada entre montañas, en el área nuclear de las estatuas-menhir. Sobre su superficie se representa armas, un escudo con escotadura y un carro (Reboreda y Nieto 2012). Su programa iconográfico puede vincularse con las estelas localizadas en la periferia como la Solana de Cabañas (Cáceres). Sin embargo, adopta cierto antropomorfismo que permite considerarla una forma híbrida entre las estelas del suroeste y las estatuas-menhir 


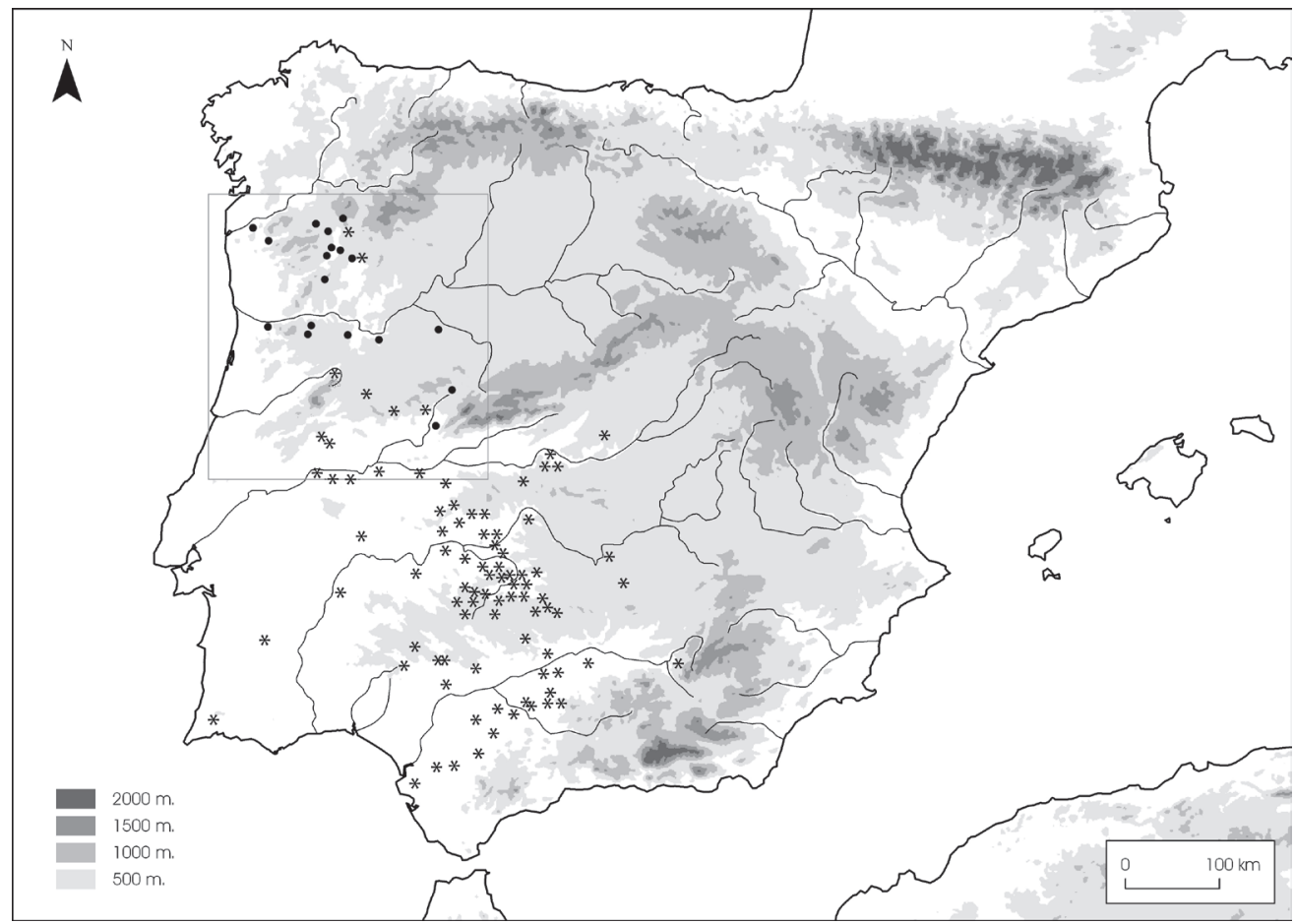

Fig. 8. Mapa de distribución de las estatuas-menhir y las estelas del suroeste.

noroccidentales (fig. 8). Este hecho y su ubicación en el entorno del río Támega son sintomáticos de que no solo la circulación de objetos se encuentra tras los contextos de interacción entre el Noroeste y el Sur de Iberia, sino que también existieron procesos de movilidad e hibridación cultural. Prueba de esto son: (1) la presencia de estelas en la Beira Alta y Tras-os-Montes (Portugal) y Orense (Galicia, España); (2) el encuentro en un mismo paisaje noroccidental entre estatuas-menhir noroccidentales y estelas del suroeste; y (3) la hibridación de ambas en una misma forma material (estela/estatua-menhir de Pedra Alta).

Este proceso de mestizaje no es el único caso en la periferia del área de dispersión de las estelas del suroeste. En el ejemplar de La Barranca del Águila (Talavera) (Celestino 2001: 355) también se hibrida la morfología de una estatua-menhir con la iconografía de una estela de guerrero. Es posible que en estos casos, al añadir los elementos iconográficos se estuviese dotando a la estatua-menhir del prestigio que aportan las armas y los objetos metálicos que se representan en el sur de la península Ibérica. Sea como fuere, parece que los rasgos antropomorfos de la estatua-menhir y la iconografía de las estelas están trabajando al unísono para materializar una imagen final mestiza. Todo ello permite pensar que los procesos de conectividad entre ambos ámbitos derivaron de la interacción directa de individuos (elites) que construyeron su identidad en el contexto de paisajes de movilidad (fig. 9).

\subsection{El emblema sub-rectangular}

La investigación de este motivo ha centrado su atención en el aspecto simbólico, interpretándose como un emblema relacionado con el estatus o el poder (Almagro-Gorbea 1993: 126; Jorge y Jorge

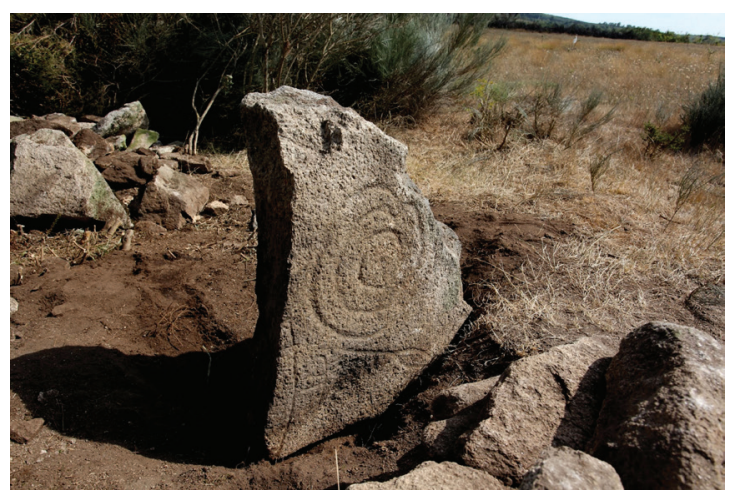

Fig. 9. La estela de Tojais, Vila Real (Alves et al. 2011). 
1993: 41; López Plaza et al. 1996: 298; Vilaça et al. 2001: 76; Bettencourt 2005). Sin embargo, el hecho de que su significado sea el resultado de una convención hace que su dimensión simbólica sea lo más difícil de interpretar. Esto se debe a que su sentido viene determinado por una ideología semiótica que desconocemos, es decir, por un conjunto culturalmente determinado e históricamente fundado de estándares hermenéuticos difícilmente recuperables a partir del registro arqueológico (Parmentier 1994: 142). Mientras que el énfasis en el simbolismo solo admite que sean interpretados como códigos visuales vinculados al poder, una aproximación relacional centrada en otros aspectos de su signicidad permite ir más allá. Una perspectiva que asuma las otras posibilidades peircianas del signo (Peirce 1994) abre nuevas posibilidades para analizar el motivo: la conexión real (como índice) y la relación de similitud (como icono).

Como índices, su presencia en el paisaje dirige nuestra atención hacia los agentes que produjeron estas formas en el pasado y cuya existencia queda garantizada por la materialidad de las estatuasmenhir. El mapa de distribución de este motivo sub-rectangular suministra una prueba material

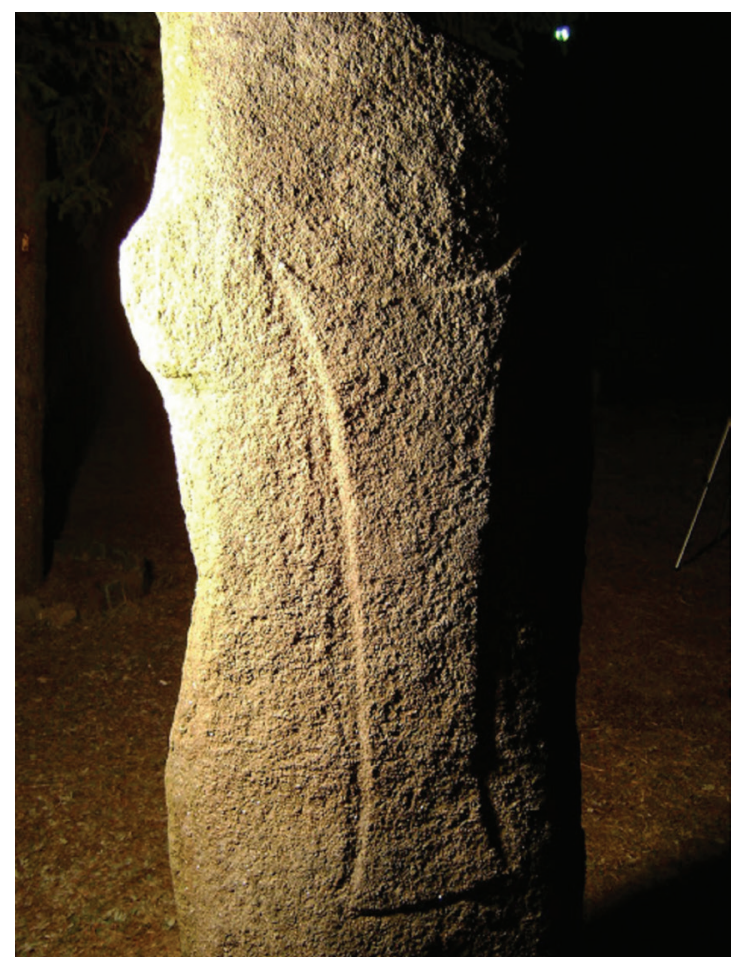

Fig. 10. La estatua-menhir de Tameirón (foto: Beatriz Comendador). de las conexiones suprarregionales en la región atlántica (Díaz-Guardamino 2011: 78). El motivo aparece representado al menos en el noroeste (región Duero-Miño), la Beira Alta, la Beira Baixa y en las provincias de Salamanca y Lérida. Por tanto, si son individuos pétreos que comparten un símbolo de poder suprarregional, estamos ante personas cuya identidad está por encima de dichas regiones o está vinculada, si se quiere, con el hecho mismo de transitar diferentes territorios. Los individuos que usan este motivo comparten un mundo cultural extracomunitario más allá del meramente local en el contexto de paisajes de movilidad.

Por otro lado, la iconicidad de estos motivos subrectangulares abre una posibilidad de análisis centrada en el referente material del icono. Tradicionalmente, se han vinculado a objetos genéricos como una estola o vestimenta ceremonial (Jorge y Jorge 1993: 39), a un kardiophilax (AlmagroGorbea 1993: 126), a un pectoral que protege las zonas vitales del individuo (Díaz-Guardamino 2010) o a un suspensorio para armas (López et al. 1996). La constatación de su posición habitual en el anverso ha permitido considerarlo en todo caso un pectoral. Sin embargo, estas asociacio-
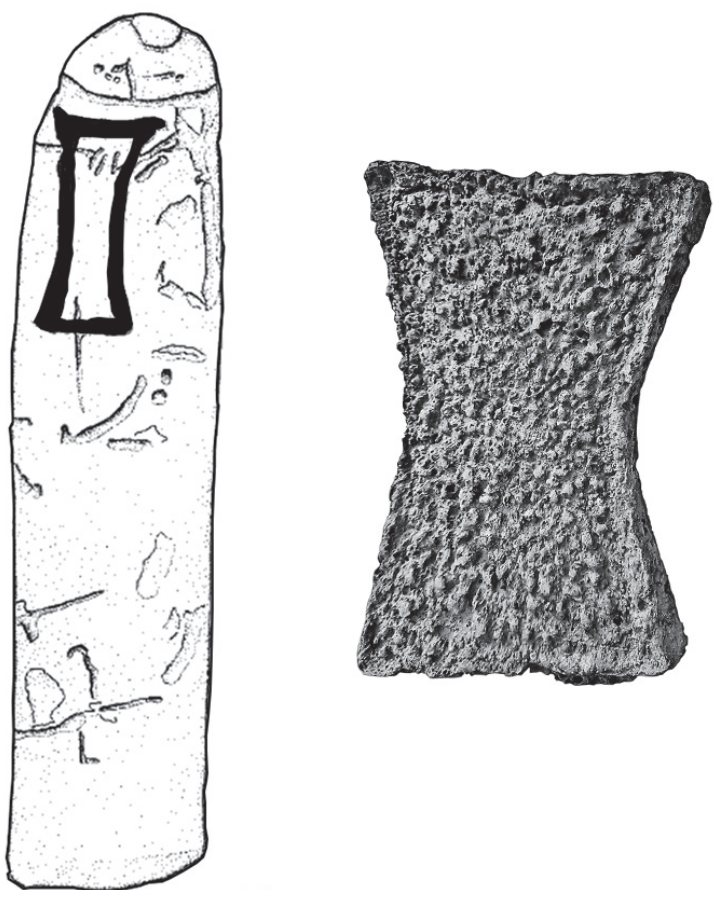

Fig. 11. La estatua-menhir de Bouça (a partir de Jorge y Jorge 1993) y un lingote de piel de toro procedente del Mediterráneo. 
nes, que refuerzan la idea de su valor simbólico o asignan un valor funcional, no ayudan a situarlo en el contexto general.

Se puede plantear una hipótesis de interpretación estableciendo una asociación entre este representamen (Pierce 1994) y la forma de piel de toro que adoptan diferentes objetos en el mundo mediterráneo y el sur de Iberia (figs. 10 y 11). Vilaça et al. (2001: 78, n11) han señalado el isomorfismo existente entre el motivo subrectangular y los lingotes chipriotas de piel de toro, desestimando, sin embargo, una posible relación entre ambos, al considerarlos un elemento exógeno al contexto occidental de las estatuas-menhir -el límite occidental de distribución de estos lingotes está en Cerdeña. En mi opinión, varios argumentos permiten matizar este problema. En primer lugar, es habitual que en la plástica de la Edad del Bronce -por ejemplo, en estelas de guerrero del suroeste- que los referentes materiales de la iconografía -liras, carros, espejos, etc.- se localicen fuera de sus áreas de dispersión y, más concretamente, en el ámbito mediterráneo. El reciente hallazgo en el noroeste del monumento de Pedra Alta con la representación de un carro y un escudo con escotadura hace extensible este hecho al noroeste de la Península. En segundo lugar, los hallazgos de lingotes y metalurgia atlántica en Cerdeña y Sicilia, así como de cerámica micénica en el sur, pero también en el noroeste de la Península (González-Ruibal 2004), sustentan la vinculación entre ambas regiones a través de redes de intercambio (López Castro 2008: 281). $\mathrm{Y}$ en tercer lugar, la representación del motivo taurodérmico se documenta en el sur de Iberia en conexión con el Bronce Final, en el yacimiento del Carambolo y en estelas del suroeste-como en el ejemplar de Cerro Muriano I (Celestino 2008: 115-116) o en el de Orellana (Badajoz) (Blas Cortina 2010: 39).

El isomofismo entre el emblema y el lingote no puede derivar en una asociación directa entre ambos. El icono representado en las estatuasmenhir más que el representamen de un lingote, puede ser, junto a este y otros objetos taurodérmicos, representamenes de la piel de toro manifiestada como sinsigno (véase Preucel 2006: 49-59). Los signos materiales, por virtud de sus cualidades materiales (cualisignos) y asociaciones (sinsignos), tienen el potencial para fijar o mutar significados y crear sentido de estabilidad o temporalidad. Por tanto, estos motivos pueden ser el representamen de un representamen en una cadena de iterabilidad marcada por las condicio- nes de existencia de la forma taurodérmica, que se materializa en diferentes soportes, lugares, contextos y tiempos.

La cualidad formal "piel de toro" surge a través de diferentes categorías objetuales (lingote, urna, pectoral, altar, etc.), se documenta en distintos contextos (pecios, templos, estelas, pinturas, esculturas, etc.), en geografías diversas (desde Egipto o Chipre hasta la península Ibérica), y a lo largo de un periodo temporal muy amplio (desde el siglo XIV a. C. hasta el siglo V a.C.). En el caso peninsular, su presencia no se constata antes del Bronce Tardío/Final. La biografía semiótica de este símbolo puede ser variopinta y diversa en los diferentes contextos donde entra en juego. Por tanto, como cualquier símbolo, su orientación semiótica, aunque no es completamente externa y suplementaria a su fuerza como icono, se entreteje con las dinámicas de valor social y autoridad, dando lugar a lo que Keane (2005: 189) ha denominado la apertura de la iconicidad. Un contexto habitual donde esta apertura tiene lugar son los contextos híbridos, fruto de contactos e interacción, que se materializan en la cultura material, como hemos visto.

El motivo subrectangular o taurodérmico podría haber estado ausente en las primeras estatuas-menhir. En aquellos ejemplares donde se representan alabardas -armas susceptibles de ser más antiguas-, bien el emblema está ausente (por ejemplo, Valdefuentes), bien pudo grabarse con posterioridad (por ejemplo, Longroiva), representándose en este último caso a través de una tipología igual a la documentada en São João de Ver. En este sentido, Díaz-Guardamino (2010) ha defendido que el conjunto de monumentos con emblema subrectangular y sin armas podrían pertenecer a los momentos más tardíos dentro de la biografía de estas formas materiales.

Aspectos tratados hasta ahora como la hibridación atlántico-mediterránea, los pectorales taurodérminos o la temporalidad de estas formas materiales se sintetizan de un modo sintomático en el tesoro del Carambolo (Sevilla). A diferencia de la mayoría de depósitos mencionados en este artículo, este depósito apareció en contexto: en un santuario y centro de poder que funcionó desde el Bronce Final. La fecha del horizonte fundacional es del 1020-810 cal. a.C. (Fernández et al. 2007: 103-104). El tesoro fue hallado bajo el suelo en un recipiente cerámico que contenía pectorales, brazaletes, placas y un collar de pseudo-sellos.

Los pectorales son taurodérmicos y paralelizables funcional e icónicamente a los motivos 
subrectangulares. Pectorales, placas y brazaletes, fueron asimismo fabricados con tecnología híbrida. Además de rasgos tecnológicos del Bronce Final atlántico - estructuras cilíndricas, decoración dispuesta en zonas, tiras de púas a la cera perdida o semiesferas-, en su elaboración también interviene el ámbito tecnológico mediterráneo -parte de las púas son huecas y se decoran con elementos típicamente mediterráneos como rosetas- (Bandera et al. 2010: 303). Este mestizaje tecnológico y estilístico permite constatar la implementación de diferentes niveles de conectividad (tecnológicos, ideológico-semiótico, sociales, etc.) y la co-presencia de personas de ambos ámbitos durante el Bronce Final (Perea y Armbruster 2008; Bandera et al. 2010), dando lugar a la creación de un mundo socio-material hibrido.

Por otro lado, aunque tradicionalmente se ha considerado un depósito homogéneo elaborado con tecnología tartésica (Carriazo 1980: 222), estudios arqueométricos y morfotipológicos recientes confirman el carácter heterogéneo de su producción, que remite a dos temporalidades en la conexión atlántica-mediterránea (Perea y Armbruster 1998; Bandera et al. 2010). La primera temporalidad es filtrada por el grupo de pectorales, brazaletes y placas que, al igual que el collar múltiple de Sintra o el bracelete de Cantonha, evidencian un contexto de conectividad e hibridación. La segunda temporalidad se filtra a través de la asociación de estas piezas del Bronce Final con el collar de pseudo-sellos, elaborado con tecnología (granulado, filigrana y soldadura) y esquema decorativo propios del Mediterráneo, y que tiene sus correlato en el noroeste en el depósito como el de Baião. El collar de pseudo-sellos fenicio señala, por tanto, el momento en el que el conjunto fue depositado (Perea y Armbruster 2008: 519).

Resulta interesante notar que los pectorales taurodérmicos y los brazaletes se ocultaron bajo el suelo del santuario en algún momento del siglo VIII-VI a.C. Así, el período en el que se amortizan los pectorales coincide con fenómenos como la colonización fenicia de la costa portuguesa, la implantación de templos betílicos en las Rías Baixas, la amortización de depósitos de hachas en la costa atlántica noroccidental o la llegada sistemática de material fenicio al noroeste. Es en ese momento cuando los navegantes fenicios abren la ruta marítima atlántica hasta el noroeste de Iberia. Este hecho probablemente tuvo lugar en detrimento de la ruta terrestre utilizada desde al menos el Bronce Tardío/Final para conectar esta región con el sur de Iberia. Así, el aumento de la importancia de la ruta marítima y el ocultamiento de los pectorales podría estar relacionado con el contexto de transición ya señalado, en donde un modelo de intercambio entre élites -basado en economías de reciprocidad $\mathrm{y}$ al que pertenecen las estatus-menhir- dio paso a otro controlado por una clase mercantil asentada en los puertos de Gadir y Onuba -basado en economías más mercantiles y en el que se integran los templos betílicos de las Rías Baixas-, y con una red de colonias y factorías en la fachada atlántica.

\section{Conclusión}

Se han analizado en este artículo las estatuas-menhir noroccidentales tomando en consideración los aspectos claves que han definido su interpretación: su cronología, relación con el paisaje y sentido iconográfico. Partiendo de esta base, estos monumentos han sido puestos en relación con un paisaje socio-material específico de acción: formas y contextos materiales de interacción durante el Bronce Tardío/Final. Todo ello nos ha permitido señalar una serie de asociaciones a través del espacio y el tiempo, establecidas icónica e indiciariamente, que acreditan diversas prácticas sociales de conectividad. Por un lado, la creación de conjuntos de objetos (acumulación) y, por otro, la modificación y creación de artefactos (hibridación). Mientras, en el primer caso, se constata el encuentro en un depósito de objetos mediterráneos y atlánticos, creando significado por asociación; en el segundo caso, se documenta reagrupación, reelaboración y trasferencia de conocimiento, creando significado por transformación. Ambos casos evidencian procesos de encadenamiento que vincularon a individuos y grupos sociales de diferentes contextos, generando contextos socio-materiales híbridos.

Las estatuas-menhir parecen materializar estos mismos procesos. Su distribución en áreas de tránsito, ricas en mineral y con distribución de objetos de interacción permite situarlas dentro de paisajes de movilidad que unieron el noroeste con el sur peninsular y el Mediterráneo. Esta circunstancia se advierte icónica e indiciariamente en las estatuasmenhir que comparten paisaje y elementos iconográficos con formas materiales del sur de Iberia, estableciendo un red de conexiones materiales (co-presencia e hibridación). En este contexto, las estatuas-menhir funcionaron en redes de intercambio y encadenamiento, basadas en mecanismos de reciprocidad y destinadas a establecer relaciones interculturales entre élites coadyuvando a crear dichos paisajes. 


\section{Nota}

1. Javier Rodríguez-Corral es investigador postdoctoral afiliado al Institute of Archaeology (University of Oxford) y miembro del GEPN (Universidad de Santiago de Compostela).

\section{REFERENCIAS Bibliográficas}

Almagro Basch, M. (1966): Las estelas decoradas del Suroeste Peninsular. Consejo Superior de Investigaciones Científicas, Madrid.

Almagro-Gorbea, M. (1993): Les Steles Anthropomorphes de la Péninsule Ibérique. Les représentations humaines du Néolithique à L àge du Fer (J. Briard, A. Duval, ed.), Éditions du Comité des Travaux Historiques et Scientifiques, Paris: 123-139.

Almeida, C.A.F.; Jorge, V.O. (1979): A estátua-menir de Faioes (Chaves). Trabalhos do Grupo de Estudos Arqueológicos do Porto, 2: 1-24.

Alves, L. B.; ReIs, M. (2011): Memoriais de pedra, símbolos de identidade: duas novas peças escultóricas de Cervos (Montalegre, Vila Real). En Vilaça 2011: 187-216.

Armbruster, B. (1995): O Bracelete de Cantonha. A Idade do Bronze em Portugal: discusos de Poder (S.O. Jorge, ed.), Museu Nacional de Arqueología, Lisboa: 104.

Armbruster, B.; Parreira, R. (1993): Inventário do Museu Nacional de Arqueologia: Colecção de Ourivesaria. Do Calcolítico à Idade do Bronze. Instituto Português de Museus, Lisboa.

Arruda, A.M. (2002): Los fenicios en Portugal. Fenicios e indigenas en el centro y sur de Portugal (siglos VIII-VI a.C.). Cuadernos de Arqueología Mediterránea, 5-6, Barcelona.

Bandera Romero, M.L. de la; Gómez Tubío, B.; Ontalba Salamanca, M.A.; Respaldiza, M.A.; Ortega Feliu, I. (2010): El tesoro de El Carambolo: técnica, simbología y poder. El Carambolo. 50 años de un Tesoro (M.L. de la Bandera Romero, E. Ferrer Albelda, eds.), Servicio de Publicaciones de la Universidad de Sevilla, Sevilla: 297-334.

Baptista, A.M. (1995): A Estátua-Menir Feminina da Ermida. A Idade do Bronze em Portugal. Discursos de poder (S.O. Jorge, ed.), Museu Nacional de Arqueología, Lisboa: 27-28.

Barceló, J.A. (1989): Arqueología, Lógica y Estadística: un análisis de las Estelas de la Edad del Bronce en la Península Ibérica. Tesis Doctoral inédita, Universitat Autónoma de Barcelona.

Bettencourt, A. (2005): A estatuaria. Arte e Cultura de Galicia e Norte de Portugal (J. M. Hidalgo Cuñarro, ed.), Nova Galicia Edicións, Vigo: 166-177.

Blas Cortina, M.A. DE (2010): Una «estela de guerrero» del Bronce final precolonial de Orellana (Badajoz), hoy en el Palacio de Meres (Siero, Asturias). Veleia: 27-28: 23-42.

Bradley, R. (2013): Hoards and the deposition of metalwork. The Oxford Handbook of the European Bronze Age (A. Harding, H. Fokkens, eds.), Oxford University Press, Oxford: 121-139.

BRANDHERM, D. (1998): Algunas consideraciones acerca de la espada de Guadalajara. ¿Un excepcional depósito desarticulado del Bronce Medio de la Meseta? Trabajos de Prehistoria, 55 (2): 177-184.

Brandherm, D. (2007): Las Espadas del Bronce Final en la Península Ibérica y Baleares. Franz Steiner Verlag, Stuttgart.

BRUCK, J. (2006): Fragmentation, personhood and the social construction of technology in Middle and Late Bronze Age Britain. Cambridge Archaeological Journal, 16 (2): 297-315.

Bueno Ramírez, P. (1983): Estatuas-menhir y armas en el Norte de la península Ibérica. Zephyrus, 36: 153-157.

Bueno Ramírez, P.; Balbín Behrmann, R.; Barroso Bermejo, R. (2008): Dioses y antepasados que salen de las piedras. Boletín del Instituto Andaluz del Patrimonio Histórico, 67: 47-61.

Carriazo, J. (1980): Protohistoria de Sevilla. En el vértice de Tartesos. Ediciones Guadalquivir, Sevilla.

Celestino Pérez, S. (2001): Estelas de guerrero y estelas diademadas. La precolonización y formación del mundo tartésico. Bellaterra, Barcelona.

Celestino Pérez, S. (2008): La precolonización a través de los símbolos. En S. Celestino, N. Rafel, X. L. Armada 2008: 107-126. 
Celestino Pérez, S.; Rafel, N.; Armada, X.L. (eds.) (2008): Contacto cultural entre el Mediterráneo y el Atlántico (siglos XII-VIII a.n.e.). La precolonización a debate. Consejo Superior de Investigaciones Científicas, Madrid.

Chapman, J. C. (2000): Fragmentation in Archaeology. People, Places and Broken objects in the prehistoric of South-eastern Europe. Routledge, Londres.

Comendador Rey, B.; Rodríguez Muñoz, V.; Manteiga Brea, A. (2011): A estatua-menhir do Tameirón no contexto dos resultados de intervención arqueolóxica no Monte Urdiñeira e o seu contorno (A GudiñaRiós, Ourense). En Vilaça 2011: 217-244.

Curado, F. P. (1984): Uma nova estela do Bronze Final na Beira Alta (Baraçal, Sabugal-Guarda). Arqueología (GEAP, Porto), 9: 81-5.

Connerton, P. (1989): How societies remember. Cambridge University Press, Cambridge.

Cruz, D. J.; Tomás Santos, A. (2011): As estátuas-menires da serra da Nave (Moimenta da Beira, Viseu) no contexto da ocupação pré-histórica do Alto Paiva e da Beira Alta. En Vilaça 2011: 117-142.

Delibes de Castro, G; Fernández-Miranda, M. (1988): Armas y utensilios de bronce en la prehistoria de las islas Baleares. Series: Studia archaeologica (Universidad de Valladolid. Departamento de Prehistoria y Arqueología), 78, Valladolid.

Díaz-Guardamino Uribe, M. (2006): Materialidad y acción social: el caso de las estelas decoradas y estatuas-menhir durante la Prehistoria peninsular. Actas del VIII Congresso Internacional de Estelas Funerárias (Lisboa 2005). O Arqueólogo Português, Suplemento 3, Lisboa: 15-33.

Díaz-Guadarmino Uribe, M. (2010): Las estelas decoradas en la Prehistoria de la Península Ibérica. Universidad Complutense de Madrid, Madrid.

DíAZ-GuARDAmino URiBe, M. (2011): Iconografía, lugares y relaciones sociales: reflexiones en torno a las estelas y estatuas-menhir atribuidas a la Edad del Bronce en la Península Ibérica. En R. Vilaça 2011: 63-88.

Díaz-Guardamino Uribe, M. (2012): Estelas decoradas del Bronce Final en la Península Ibérica: datos para su articulación cronológica. Sidereum Ana II, El río Guadiana en el Bronce Final (J. Jiménez Ávila, ed.), Anejos de Archivo Español de Arqueología LXII, Madrid: 389-416.

Fábrega Álvarez, P.; Fonte, J.; González García, F.J. (2011): Las sendas de la memoria. Sentido, espacio y reutilización de las estatuas-menhir en el noroeste de la Península Ibérica. Trabajos de Prehistoria, 68 (2): 313-330.

Fernández Flores, A.; Rodríguez Azogue, A. (2007): Tartessos desvelado. La colonización fenicia del Suroeste peninsular y el origen y ocaso de Tartessos. Almuzara, Córdoba.

Galán Domingo, E. (1993): Estelas, paisaje y territorio en el Bronce Final del Suroeste de la Península Ibérica. Complutum Extra 3, Madrid.

Galán Domingo, E. (2005): Evolución, adapatación y resitencia. En torno a las formas de intercambio de las comunidades atlánticas en contacto con el mundo orientalizante. El periodo orientalizante. Actas III simposio internacional de arqueología mediterránea de Mérida: protohistoria del mediterráneo occidental (S. Celestino Pérez, J. Jiménez Ávila, eds.), Anejos de Archivo Español de Arqueología, XXXV, Madrid: 467-475.

Galán Domingo, E.; Ruiz-Gálvez, M. (1996): Divisa, dinero y moneda. Aproximación a los patrones metrológicos prehistóricos peninsulares. Homenaje al profesor Manuel Fernández-Miranda (M.A. Querol, T. Chapa, eds.), Complutum extra, 6, Madrid: 191-215.

Galán Domingo, E.; Ruzz-Gálvez, M., (2001): Rutas ganaderas, transterminancia y caminos antiguos. El caso del Occidente peninsular entre el Calcolítico y la Edad del Hierro. Los rebaños de Gerión. Pastores y trashumancia en Iberia antigua y medieval (J. Gómez Pantonja, ed.), Casa de Velázquez, Madrid: 263-278.

Giardino, C. (1995): Il Mediterraneo Occidentale fra XIV ed VII secolo a.C.: cerchie minerarie e metallurgiche. British Archaeological Reports, International Series 612, Oxford.

González-Ruibal, A. (2004): Facing two seas: Mediterranean and Atlantic contacts in the north-west of Iberia in the first millennium BC. Oxford Journal of Arhcaeology, 23(3): 287-317.

GonzÁlez Ruibal, A. (2006): Past the last outpost: Punic merchants in the Atlantic Ocean (5th-1st centuries BC). Journal of Mediterranean Archaeology, 19 (1): 121-150. 
GonzÁlez-Ruibal, A. (2006-2007): Galaicos. Poder y comunidad en el Noroeste de la Península Ibérica (1200 a.C. - 50 d. C.). Brigantium, 18-19, Museo de San Antón, A Coruña.

GonZÁlez-García, F. J. (2009): Repensando el pasado: cambio social e iconografía guerrera en la Edad del Hierro del noroeste de la península Ibérica. Aquae Flaviae, 41: 123-152.

Guerrero Ayuso, V. M. (2008): El Bronce Final en las Baleares. Intercambios en la antesala de la colonización del archipiélago. En S. Celestino, N. Rafel , X. L. Armada 2008: 183-217.

Jorge, S. O. (1986): Povoados da Pré-história Recente (III. Inícios do II. Milénios a. C.): da Região de Chaves-Vila Pouca de Aguiar (Trás-os-Montes Ocidental). Instituto de Arqueologia da Faculdade de Letras, Porto.

JoRge, S. O. (1990): Desenvolvimento da hierarquização social e da metalurgia. Portugal das Origens à Romanização. Editorial Presença (J. Alarcão, ed.). Lisboa: 163-212.

JoRge, S. O. (1999): Stelen und Menhirstatuen der Bronzezeit auf der Iberischen Halbinsel: Diskurse der Macht. Götter und Helden der Bronzezeit. Europa im zeitalter des Odysseus. Hatje Cantz Verlag, Ostfildern: 114-122.

Jorge, S. O. (ed.) (1995): A Idade do Bronce em Portugal. Discursos de poder. Trabalhos de Arqueologia 10, Lisboa: 16-20.

Jorge, V.O. (1995): Estela de Longroiva. En( S.O. Jorge 1995): 22.

Jorge, V.O.; AlmeIDA, C.A.F. (1980): A estátua-menir fálica de Chaves. Trabalhos do Grupo de Estudos Arqueológicos do Porto, 6: 1-24.

Jorge, V.O.; Jorge, S.O. (1983): Nótula preliminar sobre uma nova estátua-menir do Norte de Portugal. Arqueologia (Porto), 7: 44-47.

Jorge, V.O.; Jorge, S.O. (1990): Statues-menhirs et stèles du nord du Portugal. Revista da Faculdade de Letras, II Serie 7: 299-324.

Jorge, V.O.; Jorge, S.O. (1993): Statues-menhirs et stèles du nord du Portugal. Les representations humaines du Néolithique à L'Age du Fer. Actes du 115 e congrès national des sociétés savantes. Avignon, 1990. (J. Briard, A. Duval, eds.), Comité des travaux historiques et scientifiques, Paris: 29-44.

Keane, W. (2003): Semiotics and the Social Analysis of Material Things. Language and Communication, 23 (2-3): 409-425.

Keane, W. (2005): The Hazards of New Clothes: What Signs Make Possible. The Art of Clothing (S. Küchler y G. Were eds.), UCL Press, Londres: 1-16.

López CASTro, J.L. (2008): Las relaciones mediterráneas en el II milenio a.C. y comienzos del I en la Alta Andalucía y el problema de la 'precolonización' fenicia. En S. Celestino, N. Rafel, X. L. Armada 2008: 273-288.

López Plaza, S.;Sevillano San José, M.C.; Grande del Brío, R. (1996): Estatua-menhir de Tremedal de Tormes (Salamanca). Zephyrus, 49: 295-303.

Martín Bravo, A.M. (1999): Los Orígenes de la Lusitania. El I Milenio a.C. en la Alta Extremadura. Real Academia de la Historia, Madrid.

Monteagudo, L. (1977): Die Beile auf der iberischen Halbinsel. Práhistorische Bronzefunde. Abteilung IX. Band 6. C.H. Beck'sche Verlagsbuchhalndlung, Munich.

OLIVIER, L. (1999): The Hochdorf "princely" grave and the question of the nature of ar-chaeological funerary assemblages. Time and Archaeology (T. Murray, ed.), Routledge, London: 109-138.

O’Toole, F. (2012): Gleninsheen Gold Gorget, c.800-700 BC in The Irish Times. A History of Ireland in 100 Objects. The Royal Irish Academy and the National Museum, Dublin: 22-23.

PARE, Сн. (2013): Weighing, commodification and money. The Oxford Handbook of the European Bronze Age (A. Harding, H. Fokkens, eds.), Oxford University Press, Oxford: 508-523.

Parmentier, R. (1994): Signs in Society: Studies in Semiotic Anthropology. Indiana University Press, Indiana.

Peirce, C. S. (1994 [1932]): The essential Peirce: selected philosophical writings 2. Harvard University Press, Cambridge. 
Perea, A. (2005): Mecanismos identitarios y de construcción de poder en la transición Bronce-Hierro. Trabajos de Prehistoria, 62 (2): 91-103.

Perea, A.; Armbruster, B. (1998): Cambio tecnológico y contacto entre Atlántico y Mediterráneo: el depósito de El Carambolo, Sevilla. Trabajos de Prehistoria, 55 (1): 121-138.

Perea, A.; Armbruster, B. (2008): Tradición, cambio y ruptura generacional. La producción orfebre de la fachada atlántica durante la transición Bronce-Hierro de la Península Ibérica. En S. Celestino, N. Rafel, X. L. Armada 2008: 509-522.

Preucel, R. W. (2006): Archaeological semiotics. Oxford University Press, Oxford.

QueIroga, F.M.V.R. (2003): War and Castros: New Perspectives in the Iron Age of Northwestern Portugal. British Archaeological Reports International Series, 1198, Oxford.

Reboreda Carreira, A.; Nieto Muñiz, E.B. (2012): A estela de Castrelo do Val. Peza do mes, octubre 2012. Museo Arqueolóxico Provincial de Ourense, Ourense.

Roвb, J. (2009): People of Stone: stelae, personhood, and society in prehistoric Europe. Journal Archaeological Method Theory, 16: 162-183.

Ruiz-GÁlvez, M. (1992): La novia vendida: orfebrería, herencia y agricultura en la Protohistoria de la Península Ibérica. Spal, 1: 219-252.

Ruiz-GÁlvez, M. (1993): El occidente de la Península Ibérica, punto de encuentro entre el Mediterráneo y el Atlántico a fines de la Edad del Bronce. Complutum, 4: 41-68.

Ruiz-GÁlvez, M. (1998): La Europa Atlántica en la Edad del Bronce. Un viaje a las raíces de Europa Occidental. Crítica, Barcelona.

Ruiz-Gálvez, M.; Galán, E. (1991): Las estelas del Suroeste como hitos de vías ganaderas y rutas comerciales. Trabajos de Prehistoria, 48: 257-273.

Sahlins, M. (1972): Stone Age Economics. Routledge, Londres.

SAnches, M.J. (1995): Estátua-menir da Bouça. En S.O. Jorge 1995: 26.

SAnches, M.J. y Jorge, V. O. (1987): A Estatua-menir da Bouça (Mirandela). Arqueologia, 16: 78-82.

Santonja Gómez, M.; Santonja Alonso, M. (1978): La estatua menhir de Valdefuentes de Sangusín. Boletín de la Asociación Española de Amigos de la Arqueología, 10: 19-24.

Senna-Martinez, J. C. (2011): La 'conexión lusitana': contactos orientalizantes y búsqueda de estaño y oro en el Centro-Norte portugués". Gadir y el Círculo del Estrecho revisados. Propuestas de la arqueología desde un enfoque social (J.C. Domínguez Pérez Pérez ed.), Consejería de Innovación, Ciencia y Empresa de la Junta de Andalucía, Cádiz: 285-296.

Silva, A. C. F. (1986): A Cultura Castreja no Noroeste de Portugal. Museu Arqueológico da Citânia de Sanfins, Paços de Ferreira.

Sousa, O. C. F. (1996): Estatuária antropomórfica pré e proto-histórica do Norte de Portugal. Dissertaçao de Mestrado. Universidade do Porto, Porto.

Steel, L. (2013): Materiality and Consumption in the Bronze Age Mediterranean. Routledge, Londres.

Strathern, A.; Steward P. J. (2005): Ceremonial exchange. A Handbook of Economic Anthropology (J. G. Carrier ed.), Edward Elgar Publishing, Northampton: 230-245.

Torres Ortiz, M. (2008): Los «tiempos» de la precolonización. En S. Celestino, N. Rafel y X. L. Armada 2008: 59-92.

Vilaça, R. (2008a): A través das Beiras: Pré-História e Proto-História. Terra Ocre, Coimbra.

VILAÇA, R. (2008b): Reflexões em torno da 'presença mediterrânea' no Centro do território português, na charneira do Bronze para o Ferro”. En S. Celestino, N. Rafel, X. L. Armada 2008: 371-402.

VIlaçA, R. (ed.) (2011): Estelas e Estátuas-menhires da Pré à Proto-história. Câmara Municipal do Sabugal, Sabugal.

Vilaça, R.; Cruz, D. J.; Santos, A. T.; Marques, J. N. (2001): A estátua-menir de 'Ataúdes’ (Figueira de Castelo Rodrigo, Guarda) no seu contexto regional. Estudos Pré-Históricos, 9: 69-82.

VilaÇA, R.; OsóRIO, M.; SAntos, A.T. (2011): Nova peça insculturada da região raiana do Sabugal (Beira Interior, Portugal): uma primeira abordagem. En Vilaça 2011: 343-367. 